\title{
A Lab demonstration of a SuperPON optical access network
}

\author{
J. Vandewege ${ }^{a}$, X.Z. Qiu ${ }^{a}$, B. Stubbe ${ }^{a}$, C. Coene ${ }^{a}$, P. Vaes ${ }^{a}$, W. Li ${ }^{a}$, \\ J. Codenie ${ }^{a}$, C. Martin ${ }^{b}$, H. Slabbinck ${ }^{b}$, I. Van de Voorde ${ }^{b}$, \\ P. Solina ${ }^{c}, P$. Obino $^{c}$ \\ ${ }^{a}$ University of Gent, IMEC, Sint Pietersnieuwstraat 41, B 9000 Gent, \\ Belgium TEL: +32926433 16 FAX: +3292643593 \\ Email: jan.vandewege@intec.rug.ac.be \\ ${ }^{b}$ Alcatel Telecom Research Centre, Antwerpen, Belgium \\ ${ }^{c}$ Centro Studie Laboratori Telecommunicazioni S.p.A. (CSELT), \\ Torino, Italy
}

\begin{abstract}
This paper contains experimental results obtained from the ACTS PLANET (Photonic Local Access NETwork) Lab demonstrator, which confirm the technical feasibility of the SuperPON concept. The SuperPON is an optical fibre-based ATM access network which can support a large number of subscriber Optical Network Units (ONUs) up to 2048 and cover a long distance of $100 \mathrm{~km}$.

This contribution shows detailed results of upstream experiments carried out on newly developed fast switching and gain controlled Optical Repeater Units (ORUs). Performance data on cascaded Semiconductor Optical Amplifiers (SOAs) include Bit Error Ratio (BER) measurements, and Signal Noise Ratio (SNR) degradation due to the introduction of cascaded SOAs. Experimental results confirm that a SuperPON can service 2048 ONUs over a distance of $100 \mathrm{~km}$.
\end{abstract}

\section{Keywords}

High splitting PON, EDFAs, SOAs, Upstream, TDM/TDMA, Burst mode BER. 


\section{INTRODUCTION}

In the continuing endeavour towards large scale broadband network access, SuperPON networks offer a unique combination of a very high bitrate continuous downlink, and a high bitrate burst mode uplink over a shared, tree-like fibre plant. Improvements in network capacity and range obtained within the ACTS PLANET project, show that a SuperPON can be a promising choice for offering a broadband basket with a mixture of distributive and interactive services to a large number of ONUs. The cost reduction offered by the capacity increase is mainly due to the physical concentration of all subscriber upstream information during propagation in the network, and to the distribution of downstream information from a single point of injection. This yields an increased sharing of the fibre plant, ORUs and the Optical Line Termination (OLT), - to be balanced with redundancy requirements - , and a more concentrated management. The range improvement can lead to extensive node consolidation, i.e. the omission of local exchanges, where switching functions are no longer required [1].

\section{THE STRUCTURE OF THE LAB DEMONSTRATOR}

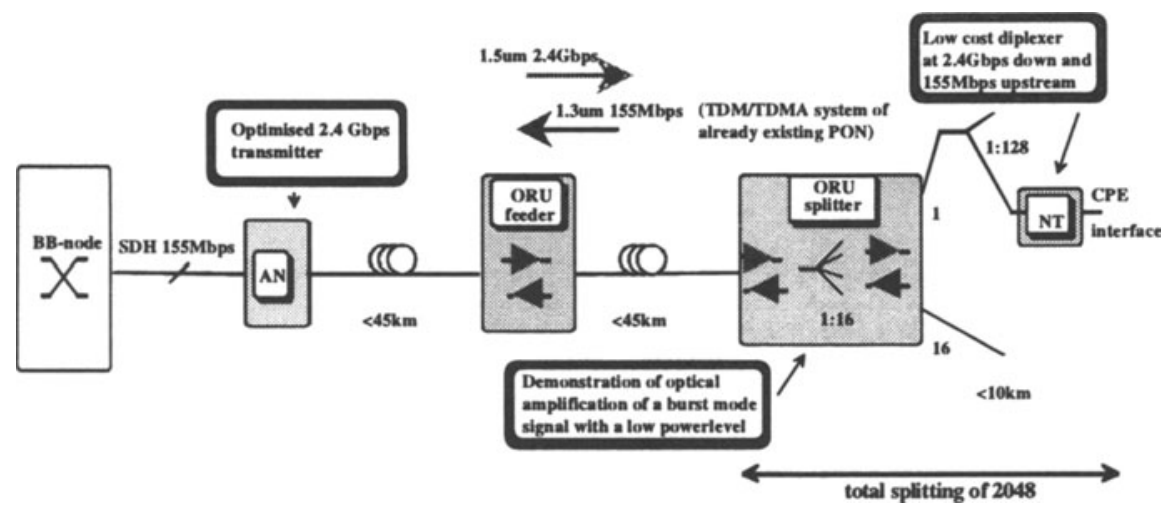

Figure 1 Overview of a SuperPON network.

Figure 1 shows a SuperPON network [2]. Downstream transmission is performed at the wavelength of $1550 \mathrm{~nm}$ with $2.5 \mathrm{~Gb} / \mathrm{s}$ Time Division Multiplexing (TDM), and upstream transmission is operated at $1310 \mathrm{~nm}$ with $155 \mathrm{Mbit} / \mathrm{s}$ ATM-based Time Division Multiple Access (TDMA). The upstream/downstream Wavelength Devision Multiplxers (WDMs) allow for single fibre operation in the drop section, whereas the ORUs and the feeders use a double fibre approach. The maximum range of the feeder section is $90 \mathrm{~km}$, and of the drop section is $10 \mathrm{~km}$.

From a single Access Node at the OLT, the SuperPON will provide 2048 ONUs with high bit-rate interactive services. The use of Optical Amplifiers (OAs) allows 
to support a much larger number of subscribers and to cover a much longer range (up to $100 \mathrm{~km}$ ) than conventional Passive Optical Networks (PONs).

A Lab demonstrator configuration [3] suitable for the study of the SuperPON concept is shown in Figure 2. It contains 2 optical amplifier branches with a total of 6 ONUs at the drop section. Two cascaded ORUs (ORU1A,B and ORU2A,B) are in parallel branches of the Amplified Splitter.

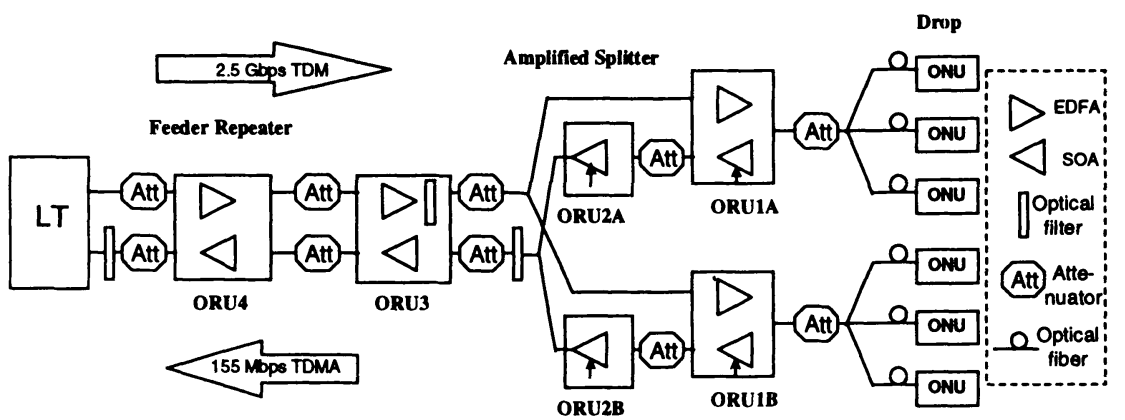

Figure 2 Network configuration of the Lab demonstrator.

\subsection{488 Gbit/s downlink}

The bit rate of the downstream link is $2.48832 \mathrm{Gbit} / \mathrm{s}$, which is a SDH STM-16 bit-rate. This rate is exactly 16 times the $155.52 \mathrm{Mbit} / \mathrm{s}$ downstream bit-rate. In the downstream direction, 3 Erbium Doped Fiber Amplifier (EDFA) stages are cascaded [4]. Two branches of the downstream network send data to six 2.488 $\mathrm{Gb} / \mathrm{s}$ receivers ( $\mathrm{RXs}$ ). As the downstream communication is in a continuous mode, no fast gain setting is required. This allows us to employ EDFAs with high gain, low Noise Figure (NF) as well as high saturation power as ORUs. Only one continuous transmitter using a TDM scheme feeds the downstream with data.

\subsection{The 155.52 Mbit/s uplink}

For upstream transmission, multiple OAs are placed in parallel branches and the optical outputs are combined at the amplified splitter section. Therefore, upstream ORUs should have nanosecond switching capability to minimise the accumulation of Amplified Spontaneous Emission (ASE) noise. Short carrier lifetime SOAs are used, which have to operate at low signal levels as they are placed behind the passive optical combiners which join the fibres from a large number of ONUs. Design for a high combining factor in the drop section is a major issue for the overall system performance. For dynamic range compression, cell by cell gain control is also required at the upstream ORU1A,B and ORU2A,B. The small signal gain of switchable SOAs is set to $22 \pm 2 \mathrm{~dB}$, and the gain of gain fixed SOAs at ORU3,4 is set to $24 \pm 2 \mathrm{~dB}$. Each SOA has maximum $4 \mathrm{~dB}$ gain uncertainty due to polarisation, wavelength and ageing effects. The minimum 
guaranteed small signal gain of the switchable SOAs is $20 \mathrm{~dB}$ for the worst case over the whole lifetime.

\section{THE UPSTREAM NETWORK TOPOLOGY}

Figure 3 illustrates the upstream network topology of the Lab demonstrator. Based on the calculated optical power budget, four cascaded UpStream ORUs (USORU1-US-ORU4) are required to compensate a total (Optical Distribution Network) ODN loss of $107 \mathrm{~dB}$ in the worst case.

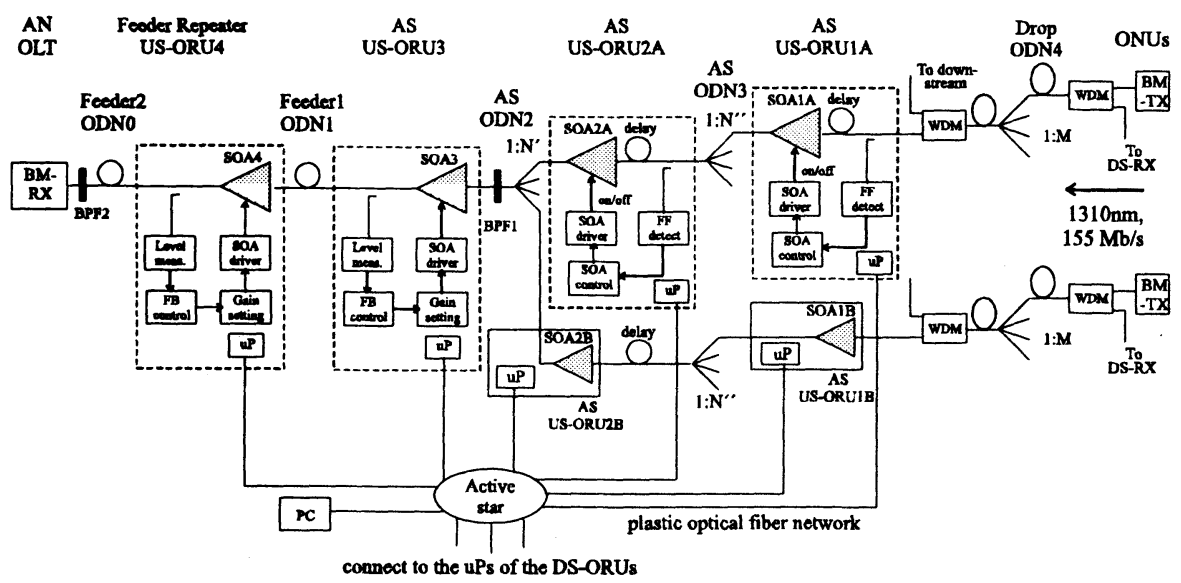

Figure 3 Upstream network topology of the Lab demonstrator.

The amplified splitter repeater uses 3 US-ORUs (ORU3, ORU2 and ORU1) for compensation of the large splitting loss. US-ORU1B and US-ORU2B have the same function as US-ORU1A and US-ORU2A. US-ORU4 is a remote feeder repeater required for extending the feeder length.

In Figure 3, the total splitting factor for upstream is $\mathbf{N}^{\prime} \times \mathbf{N}^{\prime} \times \mathbf{M}$. According to the simulation and subsystem experiments, the maximum achievable $M$ is 64 . For obtaining a total splitting factor of $2048, N$ " can be 16 or 8 , and depends on the network architecture. It is obvious that $\mathrm{N}^{\prime}$ is equal to 2 or 4 .

ODN4 to ODN0 represent the network losses, caused by optical isolators, WDM, splitter, optical fibres, bandpass filters (BPFs) and optical connections. ODN4 represents the optical loss of the drop including the losses of two cascaded WDMs, a fibre length of max. $10 \mathrm{~km}$, and a 1:64 splitter. ODN1and ODN0 are the losses of the two feeders.

\subsection{Upstream optical power budget}

1310nm bi-directional Multiple Quantum Well (MQW) laser amplifiers CQF882/E [5] from Philips are used in the upstream direction, showing a 
saturated output power of typically $10 \mathrm{dBm}$. Two external isolators are employed to prevent reflection problems.

Table 1 gives calculated upstream ODN losses in the worst case, typical case and best case respectively according to the European Telecommunication Standardisation Institute (ETSI) standard. The high loss at the drop section is typical for a high split upstream architecture. In order to avoid saturation of SOA 3 and SOA4 by ASE, a BPF with $10 \mathrm{~nm} 3 \mathrm{~dB}$ bandwidth is placed at the output of SOA2. In front of the RX a second BPF is included to reduce the offset and eventual ASE power.

Table 1 Upstream network loss with 4 ORUs for the Lab demonstrator

\begin{tabular}{lllllll}
\hline & $\begin{array}{l}\text { ODN4 } \\
(d B)\end{array}$ & $\begin{array}{l}\text { ODN3 } \\
(d B)\end{array}$ & $\begin{array}{l}\text { ODN2 } \\
(d B)\end{array}$ & $\begin{array}{l}\text { ODN1 } \\
(d B)\end{array}$ & $\begin{array}{l}\text { ODN0 } \\
(d B)\end{array}$ & $\begin{array}{l}\text { Total loss } \\
(d B)\end{array}$ \\
\hline max. loss & 31.4 & 14.1 & 15.2 & 21.5 & 24.7 & 106.9 \\
\hline typ. loss & 28.2 & 12.9 & 12.8 & 20.25 & 22.25 & 96.4 \\
\hline min. loss & 21.5 & 11.7 & 10.4 & 19.0 & 21.4 & 84 \\
\hline splitter & $1: 64$ & $1: 8$ & $1: 4$ & $45 \mathrm{~km}$ & $45 \mathrm{~km}$ & $1: 2048$ \\
/length & $/ 10 \mathrm{~km}$ & & $/ B P F 1$ & & $/ B P F 2$ & $/ 100 \mathrm{~km}$ \\
/BPF & $(\max )$. & & & & & $/ 2$ BPFs \\
\hline
\end{tabular}

\subsection{Functions of the upstream ORUs}

To obtain the timing and signal level information required for switching the SOAs and implementing the level control function, a feed forward detection technique is employed as shown in Figure 3. An activity detect and level measurement is performed on each incoming cell at the input of the switchable SOAs. The control hardware of the US-ORU1,2 contains two major parts, a feed forward loop performing fast real time control [6], and a slow feedback loop monitoring the output power of the SOA. An optical delay line is inserted at the input of the SOA for compensating the required process time of the feed forward control loop. The feedback loop is closed over a microprocessor $(\mu \mathrm{P})$ and all $\mu \mathrm{Ps}$ are linked to an active star via a plastic optical fiber (POF) network.

US-ORU3 and US-ORU4 only require the feedback loop in order to compensate slow variations caused by eventual degradation of the SOA device and temperature dependency of the drive circuitry. Each ORU uses a cell clock that triggers the complete SOA control hardware. As this cell clock is running continuously, we need the activity detect mechanism telling us whether a cell passed by or not.

\subsection{Operation of the upstream SOAs in switching mode}

To be compatible with the upstream TDMA frame format, the burst-mode gain setting of the SOAs must be stable within 3 bits $(19.2 \mathrm{~ns}$ at $155.52 \mathrm{Mb} / \mathrm{s})$. A fixed 
delay between the control signal, which initiates the switching, and the SOA gain change, can be compensated. The important parameter of the SOA switching behaviour is the rise and fall time. From Figure 4 we can see the SOA switching between the off-state and either a gain of $22 \mathrm{~dB}$ or a gain of $12 \mathrm{~dB}$ both within a time of $10 \mathrm{~ns}$, which corresponds to less than 2 bits at $155 \mathrm{Mbit} / \mathrm{s}$. The switching time is not limited by the SOA itself but by the driver electronics on the ORU board. Switching off an US-ORU can also be done within $10 \mathrm{~ns}$.

A fixed bias current allows for faster switching, but has a penalty on the isolation of the SOA in the off-state. The measured isolation of the SOA is reduced from 40 $\mathrm{dB}$ to $27 \mathrm{~dB}$, when the bias current is increased from $10 \mathrm{~mA}$ to $15 \mathrm{~mA}$.

gain $=22 \mathrm{~dB}$, rise time $=6.4 \mathrm{~ns}$

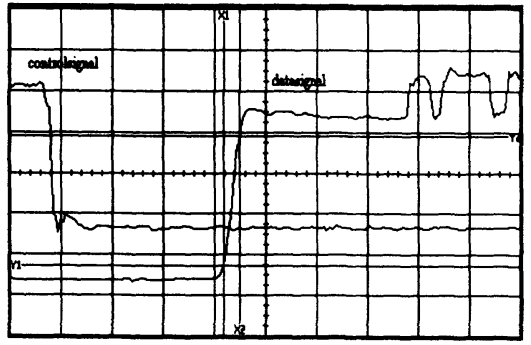

$20 \mathrm{~ns} / \mathrm{div}$ gain $=12 \mathrm{~dB}$, rise time $=9.7 \mathrm{~ns}$

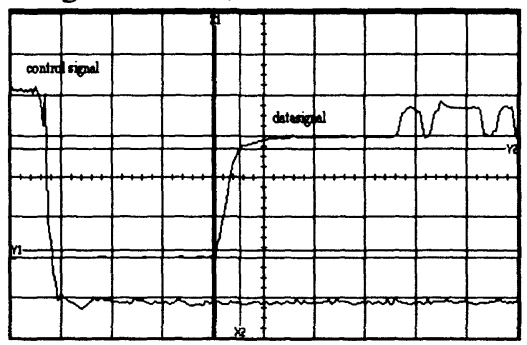

$20 \mathrm{~ns} / \mathrm{div}$

Figure 4 Switch on time of US-ORU1: $<10 \mathrm{~ns}$.

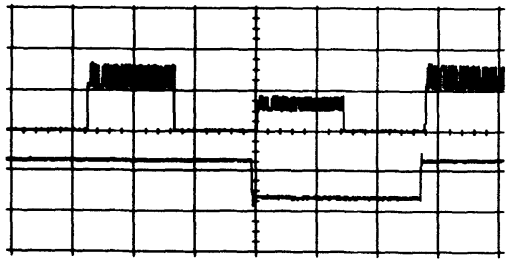

$2 \mu \mathrm{s} / \mathrm{div}$

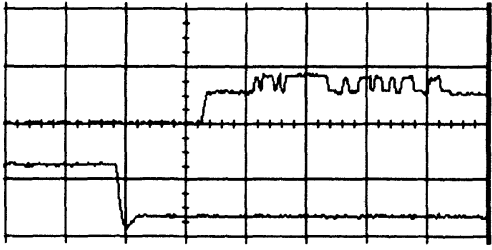

$100 \mathrm{~ns} / \mathrm{div}$

Figure 5 gain switching of the US-ORU (gain from $22 \mathrm{~dB}$ to $17 \mathrm{~dB}$ ).

Figure 5 gives a general and detailed view of the fast gain switching of the USORU. This experiment shows the gain switching of the SOA on a cell basis under the assumption that no successive cells occur in the same branch. The gain is being switched from $22 \mathrm{~dB}$ to $17 \mathrm{~dB}$. For visualisation, the level difference between cells was set to $5 \mathrm{~dB}$. However, fast gain switching on a cell by cell basis and gain control over a range of $12 \mathrm{~dB}$ has been achieved. The measured dynamic range was limited by the feed forward detection, which has a dynamic range of 12 dB. It should be noted that this limitation is only presented in the Lab demonstrator, because we use an existing APON system for evaluation of the technical feasibility of the SuperPON network. Within the ACTS PLANET project a field trial is under development, where downstream grants will be extracted by an Operation, Administration \& Maintenance ONU (OAM-ONU) 
located at the amplified splitter. This allows us to do the real time control of the SOAs without activity detection.

\section{EXPERIMENTAL RESULTS}

\subsection{Performance of the operation in Continuous Wave $(\mathrm{CW})$ mode}

In the uplink, the main issue is to amplify weak upstream signals in order to obtain a maximum loss of the drop section. A low input power results in a reduced SNR because of the ASE power from the SOA. The signal-spontaneous (sig-sp) beat noise is caused by beating of the signal with spontaneous emission on a square-law photo detector. This is a fundamental limitation on the receiver SNR when the signal is relative strong. The spontaneous-spontaneous (sp-sp) beat noise contribution is generated by heterodyne mixing between frequency adjacent ASE components, which predominates in the total ASE noise when the input signal is getting weak.

For investigating the maximum power budget of the drop, or minimum input level of SOA1, a first subsystem depicted in Figure 6 containing one continuously activated SOA and two ODNs was tested. The two ODNs are emulated with optical variable attenuators. Here the loss of ODN4 and ODN3 represents the drop section loss and the feeder loss respectively. The loss of the feeder ODN3 was set in such a way that the incoming signal power at the $R X$ is about $-25 \mathrm{dBm}$ peak, so that the system performance will be not limited by the RX sensitivity. A $9 \mathrm{~nm} \mathrm{BPF}$ is placed in front of a CW- RX.

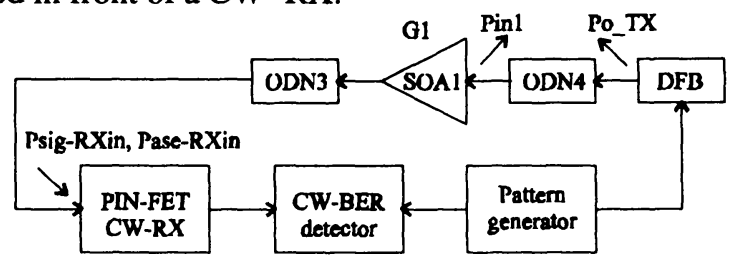

Figure 6 Set-up of 1 SOA in CW mode operation.

Table 2 Parameter settings of the 1-SOA set-up

\begin{tabular}{llllll}
\hline $\begin{array}{l}\text { Po_TX } \\
(\text { peak })\end{array}$ & $\begin{array}{l}\text { Drop ODN4 } \\
1: 128 / 10 \mathrm{~km}\end{array}$ & $\begin{array}{l}\text { Pinl } \\
(\text { peak }) \\
(\mathrm{dB})\end{array}$ & $\begin{array}{l}\text { G1 } \\
(\mathrm{dB})\end{array}$ & $\begin{array}{l}\text { Feeder ODN3 } \\
\text { (with 9 nm BPF1) }\end{array}$ \\
\hline Case1 $+1.5 \mathrm{dBm}$ & $34.5 \mathrm{~dB}$ & $-33 \mathrm{dBm}$ & 20 & $12 \mathrm{~dB}$ \\
\hline Case $2+1.5 \mathrm{dBm}$ & $34.5 \mathrm{~dB}$ & $-33 \mathrm{dBm}$ & 25 & $17 \mathrm{~dB}$ \\
\hline
\end{tabular}

Table 2 lists two sets of parameters for this 1-SOA set-up. Here Po_TX is the peak output power of the Transmitter (TX) used in the experiment; Pin1 is the peak input power of SOA1. In Case1, the gain of SOA1 was set to $20 \mathrm{~dB}$ (fiber to fiber gain), and ODN3 was set to $12 \mathrm{~dB}$ including BPF1. In Case2, the gain of SOA1 
was increased to $25 \mathrm{~dB}$ (fiber to fiber gain), and ODN3 was increased by $5 \mathrm{~dB}$. The BER was measured versus the input power of SOA1. When Pin1 is equal to $35 \mathrm{dBm}$ (peak), the measured CW-BER is $1.9 \times 10^{-10}$ for Case 1 , and $3 \times 10^{-10}$ for Case2.

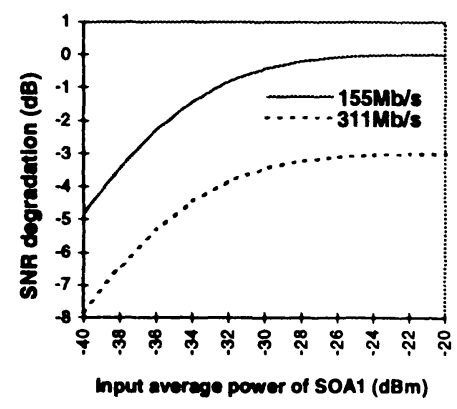

Figure 7 SNR degradation versus input average power of SOA1.

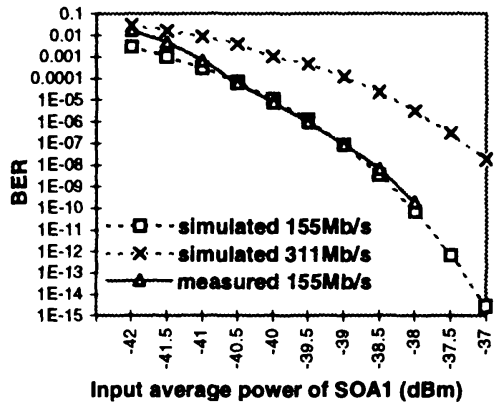

Figure 8 BER versus input average power of SOA1.

Figure 7 shows the calculated SNR degradation as a function of the mean signal power at the SOA input. The graph indicates that the SNR penalty is approximately $1.4 \mathrm{~dB}$ at an input average level Pin 1 of $-34 \mathrm{dBm}$, and $3.4 \mathrm{~dB}$ at an input level Pin 1 of $-38 \mathrm{dBm}$, both at a bit-rate of $155 \mathrm{Mbit} / \mathrm{s}$. The performance at a bit rate of $311 \mathrm{Mb} / \mathrm{s}$ has been also evaluated, as the upstream data rate will be upgraded to $311 \mathrm{Mb} / \mathrm{s}$ in the field trial.

Figure 8 compares the simulated and the measured BER. The BER was calculated based on the SNR at the RX. It is clear that the two curves at $155 \mathrm{Mb} / \mathrm{s}$ in Figure 8 are merged together, this indicates that the measurement result agrees with the calculation. From the results shown in Figure 8, the minimum input signal power required to obtain a BER less than $10^{-9}$ is - $38 \mathrm{dBm}$ (avg.) at $155 \mathrm{Mbit} / \mathrm{s}$. However, $3 \mathrm{~dB}$ system margin is necessary to be added, since the SNR is degraded quickly when the incoming signal is too weak. Therefore, we can only set the minimum input power to $-35 \mathrm{dBm}$ (avg.) taking into account the margin. This value corresponds to a drop loss of $33.5 \mathrm{~dB}$, which contains the loss from a 1:64 splitter, $10 \mathrm{~km}$ fiber length and other passive optical components at the drop section (the worst case) and $2 \mathrm{~dB}$ margin of the power budget.

From the above analysis, one can see that the maximum achievable optical power budget of the drop section is not dependent on the gain setting of the first SOA if this gain is high enough. The budget is limited by the sp-sp beat noise of SOA1. Therefore, the NF of SOA1 plays an important role in the whole system performance. Moreover, it is clear that ODN3 can be increased by an extra $5 \mathrm{~dB}$ if G1 is increased from $20 \mathrm{~dB}$ to $25 \mathrm{~dB}$.

To investigate the SNR degradation due to the cascaded SOAs, CW-BER measurements were performed on similar 2-SOA and 3-SOA set-ups. The measurements were based on a maximum length $2^{23}-1$ Pseudo Random Binary 
Sequence (PRBS) pattern generated at $155.52 \mathrm{Mb} / \mathrm{s}$. The decision threshold level was manually set in the middle of the eye opening.

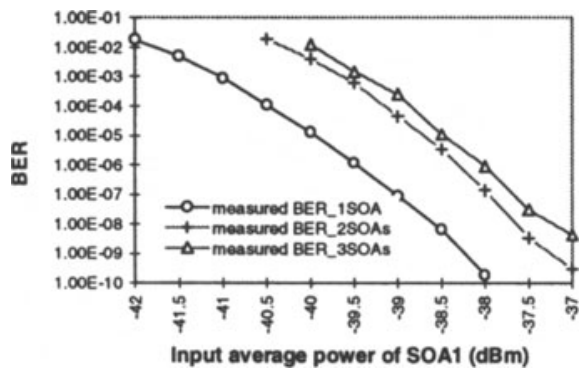

Figure $9 \mathrm{BER}$ as a function of the input average power of SOA1.

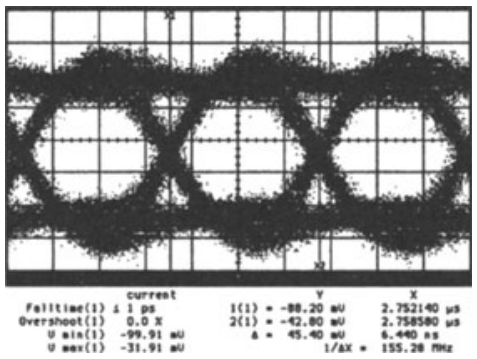

Figure 10 Eye diagram of $155 \mathrm{Mbit} / \mathrm{s}$ signal having passed through 3 SOAs.

Figure 9 shows the BER as a function of the input average power at SOA1. The BER curves for 1 SOA, 2 SOAs and 3 SOAs are marked with circles, crosses, and triangles respectively. In the configuration with $1 \mathrm{SOA}$, a minimum input power of $-38 \mathrm{dBm}$ (avg.) was found to cause a BER of $1.9 \times 10^{-10}$. After the insertion of the second SOA, a BER of $3 \times 10^{-10}$ was measured for an input power of $-37 \mathrm{dBm}$. For the 3-SOA configuration, a BER less than $1 \times 10^{-9}$ was found at an input level of $-36.5 \mathrm{dBm}$.

Figure 10 gives an eye diagram measured at the $\mathrm{RX}$. The input mean power at SOA1 was - $36.5 \mathrm{dBm}$ (avg.) and the received average power was - $28 \mathrm{dBm}$ (avg.) We can conclude that there is $1 \mathrm{~dB}$ degradation on CW-BER from 1-SOA to 2-SOA set-up, and that the total system penalty is $1.5 \mathrm{~dB}$ for the worst case scenario, due to the introduction of SOA2 and SOA3. The penalty will be less if the network topology is optimised, whereas the above experiments were performed according to the worst case scenario emulation.

\subsection{Performance of the operation in switching mode}

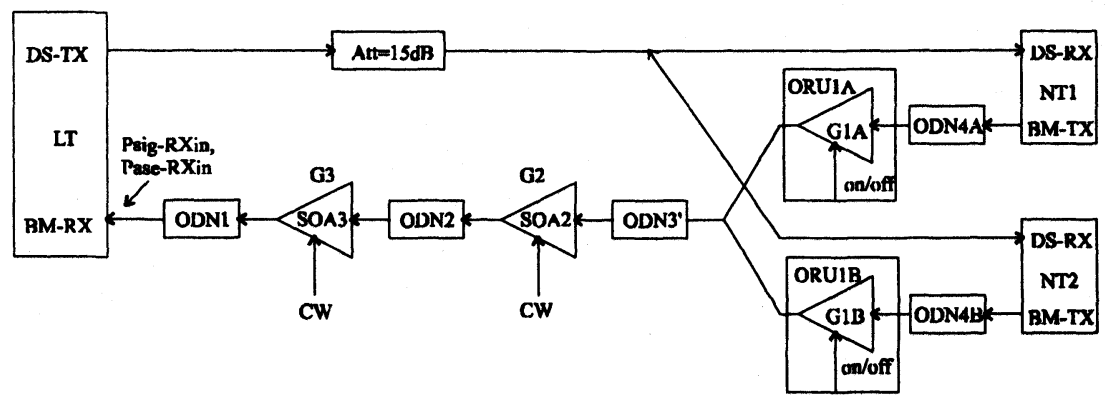

Figure 11 Set-up with 3 cascaded US-ORUs and two switchable branches. 
Figure 11 illustrates a set-up with 3 cascaded SOAs and two switchable branches using an Alcatel ATM-PON system [7]. In this experiment, optical power budgets of drop A (ODN4A) and drop B (ODN4B) were measured, and the power levels at SOA1A,B required for a BER of $10^{-9}$ were also investigated, where USORU1A,B were operated in switching mode. Results from two different cases (with and without gain control of US-ORU1) are compared. Table 3 lists the parameter settings for this experiment.

Table 3 Parameter settings for the set-up operating in switching mode with gain control (ctrl.)

\begin{tabular}{lllllll}
\hline $\begin{array}{l}\text { spec.ODN4 } \\
\text { (split }\end{array}$ & $\begin{array}{l}\text { gain ctrl. } \\
\text { G1 }\end{array}$ & $\begin{array}{l}\text { ODN3 } \\
\text { (split) }\end{array}$ & $\begin{array}{l}\text { gain } \\
\text { fixed } \\
\text { Gange) }\end{array}$ & $\begin{array}{l}\text { ODN2 } \\
\text { (split) }\end{array}$ & $\begin{array}{l}\text { gain } \\
\text { fixed } \\
\text { G3 }\end{array}$ & $\begin{array}{l}\text { ODN1 } \\
\text { (range) }\end{array}$ \\
\hline $32 \mathrm{~dB}$ & $22 \mathrm{~dB}$ & $16 \mathrm{~dB}$ & $22 \mathrm{~dB}$ & $18 \mathrm{~dB}$ & 24 & $24 \mathrm{~dB}$ \\
$(1: 64$ & $\begin{array}{l}\text { (weak cells) } \\
(1: 8)\end{array}$ & & $(1: 4)$ & $\mathrm{dB}$ & $(45 \mathrm{~km})$ \\
$/ 10 \mathrm{~km})$ & $\begin{array}{l}12 \mathrm{~dB} \\
\text { (strong cells) }\end{array}$ & & & & & \\
\hline
\end{tabular}
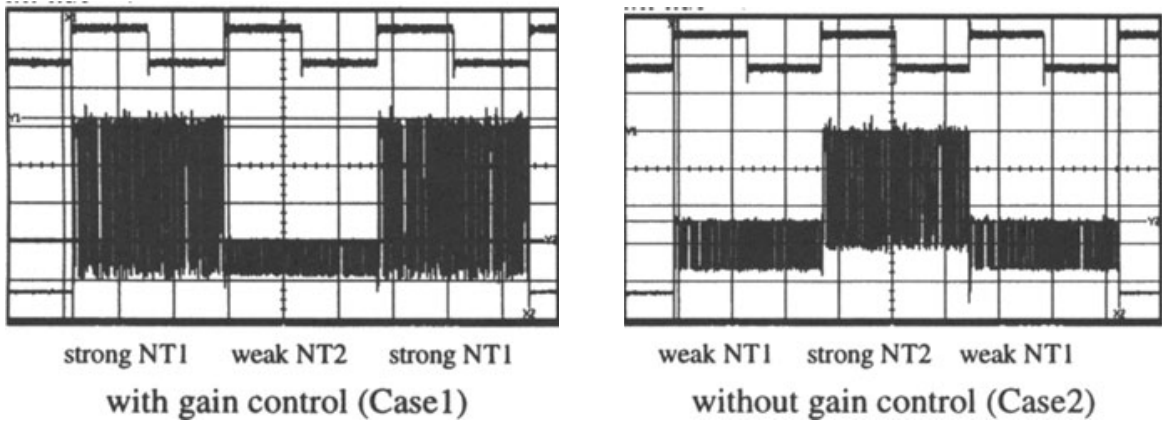

Figure 12 Burst data stream in the front of the RX.

Figure 12 shows upstream data streams measured in front of the RX, which contain cells sent by Network Termination 1 (NT1) with $50 \%$ BW allocation from Branch A, and cells sent by NT2 with $25 \%$ BW allocation from Branch B. In Case1, a strong burst from NT1 is followed by a weak burst from NT2, where the gain is set to $12 \mathrm{~dB}$ for the strong cells from NT1 and $22 \mathrm{~dB}$ for the weak cells from NT2. In Case 2, a weak burst from NT1 is followed by a strong burst from NT2, where the gain of both US-ORU1A,B was set to $22 \mathrm{~dB}$ without gain control. The achievable Dynamic Range (DR) of the two drops was measured in the case of gain control of US-ORU1A (B) and without gain control respectively, by creating a level difference between drop A and drop B (DR-AB1 and DR-AB2). The measured dynamic ranges between two drops are listed in Table 4 . 
From the experimental results, we can see that the dynamic range DR-AB1 (case1) is $16.5 \mathrm{~dB}$ with gain control, and $13.5 \mathrm{~dB}$ without gain control. The measured DR is limited by the experimental set-up, in which the variable optical attenuator has been set to $0 \mathrm{~dB}$, so DR-AB1 (with gain control) could be higher if the loss of the drop A could go lower. The dynamic range DR-AB2 is $23 \mathrm{~dB}$ with gain control, and $15 \mathrm{~dB}$ without gain control, which is improved $8 \mathrm{~dB}$ by using the gain control.

Table 4 Measured dynamic range between two drops

\begin{tabular}{lllll}
\hline & $\begin{array}{l}\text { Case1,dB } \\
\text { (with ctrl.) }\end{array}$ & $\begin{array}{l}\text { Case1,dB } \\
(\text { w/o ctrl.) }\end{array}$ & $\begin{array}{l}\text { Case2,dB } \\
\text { (with ctrl.) }\end{array}$ & $\begin{array}{l}\text { Case2,dB } \\
\text { (w/o ctrl.) }\end{array}$ \\
\hline $\max . P i n 1 \mathrm{~A}(\mathrm{dBm})$ & $>-9.3$ & -11.8 & & \\
\hline $\min . P i n 1 \mathrm{~B}(\mathrm{dBm})$ & -25.8 & -25.3 & & \\
\hline DR-AB1 $(\mathrm{dB})$ & $>16.5$ & 13.5 & & -11.3 \\
\hline $\max . P i n 1 \mathrm{~A}(\mathrm{dBm})$ & & & -4.3 & -26.3 \\
\hline $\min . P i n 1 \mathrm{~B}(\mathrm{dBm})$ & & & -23 & 15 \\
\hline DR-AB2 $(\mathrm{dB})$ & & & & \\
\hline
\end{tabular}

Moreover, a 5-7 dB degradation on the minimum input level of SOA1A,B for a BER of 1E-9 at the LT was observed when the set-up was changed from CW mode operation to switching mode. This is because the ASE power (or offset) varies a lot from cell to cell, so an optimised BM-RX with a cell based offset compensation is required. However, we use the existing APON LT, which was designed for PON applications where no ASE power variation exists. The actual used BM-RX is AC coupled, and the threshold is set to a fixed level with respect to the peak optical power level, and cannot be optimised on a cell basis for the SuperPON applications. The effect is illustrated in Figure 13.

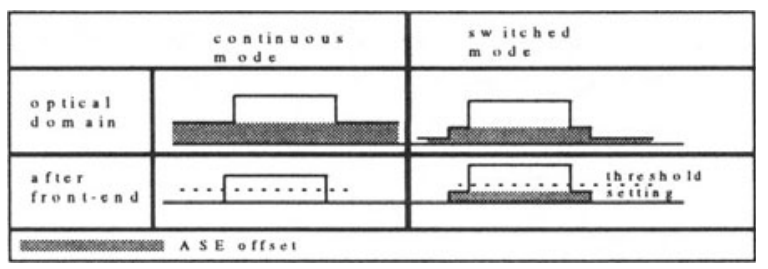

Figure 13 Penalty caused by the current BM_RX design.

By observing the optical signal quality at the input of the BM-RX, we can conclude that the measured minimum input levels of SOA1A,B are limited by the threshold setting of the existing BM-RX. The achievable optical power budget can be increased significantly by using a new receiver optimised for burst mode signals containing strong and variable ASE power, which is currently in development. 


\section{CONCLUSIONS}

Various upstream ORU designs have been completed. Fast on/off switching and gain control of the SOAs results in an important decrease of the accumulation of noise and a substantial reduction of the dynamic range requirements within the system.

Different network topologies have been evaluated and emulated by the Lab demonstrator set-up. The experimental results indicate that even with the worst case scenarios an upstream splitting ratio of 2048 and a range of $100 \mathrm{~km}$ are feasible at $155 \mathrm{Mb} / \mathrm{s}$ if an optimised burst-mode receiver is used.

\section{ACKNOWLEDGMENTS}

This work was supported by the European Commission within the ACTS project AC050 "PLANET". We thank our PLANET partners for their co-operation, especially Philips Optoelectronics Centre for the $1310 \mathrm{~nm}$ MQW SOAs, and Alcatel Optronics for the EDFAs, STM-16 transmitters and 1.3 DFB lasers used in the Lab demonstrator.

\section{REFERENCES}

1. Denis. J.G. Mestdagh and Claire M. Martin, "The SuperPON Concept and its Technical Challenges", Proc. of IFIP/IEEE Broadband Communications 1996.

2. Ingrid Van de Voorde, M.O. van Deventer, P.J.M. Peters, P. Crahay, E. Jaunart, A.J. Philips, J.M. Senior, X.Z. Qiu, J. Vandewege, J.J.M. Binsma, P.J. Vetter, "Network Topologies for SuperPON", Proc. of OFC'97.

3. Claire M. Martin, Hans Slabbinck, Peter Vetter, Xing-Zhi Qiu, Jan Vandewege, Paolo Solina, Denys Haux, Gerlas van den Hoven, Andre Boot, "Realisation of a SuperPON demonstrator", Proc. of NOC "97.

4. Hans Slabbinck, Claire Martin, Ingrid Van de Voorde, Brecht Stubbe, Peter Vaes, Xing-Zhi Qiu, Jan Vandewege, Paolo Solina, Pietro Obino, "Evaluation of a SuperPON Demonstrator”, Proc. of SPIE '97.

5. Luuk F. Tiemeijer, Peter J. A. Thijs, Teus van Dongen, J.J.M. Binsma, and Edwin J. Jansen, "Polarization Resolved, Complete Characterization of 1310 nm Fiber Pigtailed Multiple-Quantum-Well Optical Amplifiers", J. LT., vol. 14, pp. 1524-1533, 1996.

6. B. Stubbe , P. Vaes, L. Gouwy, C. Coene, X. Z. Qiu, B. Staelens, J. Vandewege, H. Slabbinck, C. Martin, I. Van de Voorde, "Embedded real time control of optically amplified repeaters in broadband access networks" Proc. of SPIE ‘97.

7. X. Z. Qiu, C. Martin, J. Zhou, B. Stubbe, C. Coene, B. Staelens, I. Van de Voorde, J. Vandewege, "Upstream Burst-mode Experiments using Semiconductor Optical Amplifiers as Repeaters for a SuperPON", Proc. of Optical Amplifier and their Applications 1997. 